\title{
Density and the Journey to Work
}

\author{
DAVID M. LEVINSON AND AJAY KUMAR
}

\begin{abstract}
This paper evaluates the influence of residential density on commuting behavior across U.S. cities while controlling for available opportunities, the technology of transportation infrastructure, and individual socioeconomic and demographic characteristics. The measures of metropolitan and local density are addressed separately. It is suggested that metropolitan residential density serves principally as a surrogate for city size. Markets react to high interaction costs found in large cities by raising density rather than density being a cause of those high costs. Local residential density measures relative location (accessibility) within the metropolitan region as well as indexing the level of congestion. Regressions are conducted to predict commuting time, speed, and distance, by mode of travel on a cross-section of individuals nationally and city by city. The results indicate that residential density in the area around the tripmaker's home is an important factor: the higher the density the lower the speed and the shorter the distance. However, density's effect on travel time is ambiguous; speed and distance are offsetting effects on time. The paper suggests a threshold density at which the decrease in distance is overtaken by the congestion effects, resulting in a residential density between 7,500 and 10,000 persons per square mile (neither the highest nor lowest) with the shortest duration auto commutes.
\end{abstract}

\section{Introduction}

$T$ he interrelationships among density, city size, demographics, and travel 1 demand patterns have long been discussed at the national or metropolitan scale (Voorhees 1968; Richardson 1973; Steiner 1994; Frank and Pivo 1994). With recent concerns about air quality damage caused by highway transportation, this issue has become more relevant for public policy (Bae 1992). Debate remains about many of the details of the interactions between variables and their potential implications for transportation policy.

David $M$. Levinson is a researcher and graduate student at the Institute of Transportation Studies, University of California at Berkeley; Ajay Kumar is a transportation economist at the World Bank. They would like to thank Susan Liss of the U.S. Department of Transportation for providing the NPTS data. An earlier version of this paper was presented at the Western Regional Science Association meeting in Napa, California (Feb. 1996). The authors would like to thank all who commented at the time, in particular Richard Crepeau. They also thank the staff of the Montgomery County Planning Department, and the University of California at Berkeley. All errors, opinions, and analysis in the text remain the responsibility of the authors.

Submitted Dec. 1995; revised June, Nov. 1996.

(c) 1997 Center for Business and Economic Research, University of Kentucky.

Published by Blackwell Publishers, 350 Main Street, Malden MA 02148, US,

and 108 Cowley Road, Oxford, OX4 IJF, UK. 
Newman and Kenworthy (1992), for instance, criticize earlier investigations into the issue of the effects of urban form on travel, stating that "U.S. data constitute a poor sample for examining the effects of density on travel and gasoline use, as there is very little density variation on a metropolitan basis." They conclude that the higher the density, the lower the gasoline consumption, suggesting an exponential relationship between density and gasoline use, and find significant effects above 30 persons per hectare (ha) or 7800 persons per square mile. This is consistent with Pushkarev and Zupan (1977), who analyzed data on the New York region and found that there exists a significant positive relationship between density and transit trips. They also found that, on average, lower income households travel less than other households at all densities. Goodwin (1975) used the 1971-72 British national travel survey to evaluate the relationship between density and several travel related characteristics, concluding that households in high density areas made the same number of trips overall, but fewer by automobile.

However, analyzing data from both the Federal Highway Administration's Highway Statistics 1990 and the Texas Transportation Institute, Dunphy and Fisher (1994) argue that metropolitan residential density explains only 15 percent of the variation in per capita vehicle miles traveled among metropolitan areas over one million persons. Gordon et al. (1989a), using data derived from Landsat photographs to compute the ratio of residential population to residential land at the metropolitan level, conclude that metropolitan residential densities and commuting times are positively associated.

The conflicting findings between researchers indicate a difficulty in determining whether density increases or reduces total commuting time and distance. In part that is due to multiple measurements of density: local vs. metropolitan, and residential vs. employment. In part it is the ambiguity about what a "density" measurement is really measuring: is local density really capturing the number of people per unit area, the level of congestion, or the distance from the center(s) of the region (and implicitly the distance to other people)? Is metropolitan density really just capturing city size? The answer to these questions has important implications for land use policies which hope to change travel behavior by changing land use densities.

It is argued that at the metropolitan level, average density is principally a surrogate for city size. Aside from its accessibility benefits (agglomeration economies), increased density brings about costs that are undesirable (less space per person, more expensive construction, higher land costs, congestion). Thus densification, like polycentricity, is primarily a market response to contain or reduce otherwise high interaction costs found as cities increase in population, (in particular journey-to-work times, but also including other travel 
costs such as those of firm-to-firm interactions (Sivitanidou 1995) and nonwork travel (Handy 1993)), rather than a cause of those travel times.

Within the city, density remains largely a measure of distance from the center(s) of the region. Researchers agree that local density is positively associated with non-auto mode shares for several reasons: higher congestion in the urban core, greater frequency of transit service, and lowered access to transit times. Density's effect on overall commuting times is less straightforward. Clearly the higher the density (and the closer to the center of the region) the more possible destinations there are that can be reached in the same distance. Just as clearly density and congestion are paired, leading to slower speeds, at least by the automobile. Because congestion effects are non-linear: at low flows travel times are almost unaffected by the marginal traveler but above a critical threshold each one percent increase in traffic increases time by more than one percent; a non-linear association between density and highway travel times is expected. When increasing density from a lower level, the gain in coverage by auto outweighs the reduction in speed; at higher densities the opposite holds. Note also that the highest density neighborhoods are only found in the centers of the largest metropolitan areas.

The 1990/91 Nationwide Personal Transportation Survey (NPTS) is used to analyze the effect of local and metropolitan residential density, the number of edge cities, rate of growth, highway speed, transit availability, and demographics and socio-economics on commuting time, distance, and speed of individual commuters. In the next section the relationships between urban structure and travel behavior are discussed in order to develop specific hypotheses to test with the available database. That section examines the influence of a variety of variables (residential density, city size, growth rate, transportation network structure, income, gender, and age) on time, speed, and distance, and presents general observations and hypotheses. Then the NPTS database used in this analysis is discussed. These discussions are followed by the results from several regression analyses across cities nationally, individuals nationally, and individuals in specific cities to isolate inter- and intrametropolitan variation. The paper concludes that while density matters statistically, particularly regarding distance and speed, its influence is relatively weak - suggesting that density makes a poor choice as a policy instrument to influence individual travel times.

\section{Theory and Hypotheses}

The relationship between density and travel behavior is complex; the empirical pieces are not entirely in concord. Furthermore, theories of urban economics do not give unambiguous predictions about the amount of travel undertaken (in terms of time or distance) as a function of key spatial variables, 
primarily because the axioms of the standard model require resolving empirical factors.

First, it has been long observed that the level of interaction between any two places declines with separation (Isard 1956), that is, the desirability of a commute between home and work declines with increasing travel time, cost, and effort. The gravity model, which measures this phenomenon, has been confirmed many times (Mitchelson and Wheeler 1986; Scott 1988; Cervero 1989; Levinson and Kumar 1995a). The time spent traveling to work and other destinations must be nested within a broader activity framework (Pas 1980; Levinson and Kumar 1995b); and time spent traveling necessarily reduces the available time for other activities, which helps explain the size of this disutility.

Second, geometry dictates that the cumulative number of opportunities (for instance jobs or houses) increases with the area covered. In the case of uniform density, the number increases from a point as the square of distance, though it must be recognized that opportunities are not evenly distributed. For instance, resident workers of larger cities have more jobs available at farther distances than do residents of smaller cities, who more quickly reach the boundary of the metropolitan region and levels of very low intensity use. It has generally been observed, and confirmed in Table 1, that larger cities have longer average commutes (in both distance and time).

It is apparent that the first and second factors are offsetting; while costs rise with distance, so do opportunities. Because commuters are neither time minimizing nor opportunity maximizing, some trade-off between the two takes place, leaving commutes longer than the minimum required (Giuliano and Small 1993), but still constraining the size of the city.

To unpack this process, commuting distance, speed, and duration can be estimated as functions of several measurable factors. Conceptually, the expected commuting time (distance, speed) for an individual can be viewed to depend on several factors: residential density which represents both the spatial location of homes as well as congestion levels, variables representing the number and pattern of employment opportunities available and how fast the number is changing, transportation technology and level of service, and individual socioeconomic and demographic factors. This section presents specific hypotheses of the influence of local and metropolitan density, the number of edge cities, the metropolitan growth rate, the use of freeways and presence of heavy rail, and demographics and socio-economics (income, gender, and age) on travel time, speed, and distance separately for auto and transit users. The tests of the hypotheses using ordinary least squares regression are presented in subsequent sections.

Metropolitan density. Consistent with theory, average metropolitan residential density, and thus the proportion of individuals living at specific 
(local) residential densities within a city, is highly dependent on city size. While it would be desirable to distinguish spatial extent and density, the variables are too highly correlated in the available data to be able to do so with accuracy. Markets react in several ways to the increased distance that would otherwise need to be covered as cities expand horizontally over space. Historically, density was increased, both uniformly and particularly in downtown. More recently, multiple centers were spawned. This suggests that density (or polycentricity), rather than being a cause of high travel times, may be more properly viewed as a response to otherwise long distances designed to contain commuting costs. Therefore, research which finds a positive association of average commuting duration with density (or the number of centers), may have found what historically explains the density (or polycentricity), rather than vice versa.

Table 1 shows the land use variables (1990 population, ten year growth rate, and metropolitan and urbanized area density) as well as transportation variables (mean travel time, distance, speed, trip frequency, and vehicle ownership) for each Metropolitan Statistical Area (MSA) or Consolidated Metropolitan Statistical Area (CMSA) with a population greater than $1,000,000$ persons, as defined by the U.S. Bureau of the Census. The cities range in size from the Rochester, NY MSA (one million persons), to the New York City CMSA (over 18 million persons). Sample rates vary between cities as several Metropolitan Planning Organizations (MPO) (in particular New York and Indianapolis) paid for the collection of additional responses.

As shown in Table 1, urbanized area residential density (URBDENS) and city size are positively correlated, and clearly larger cities have longer travel times. This was also found in work by Gordon et al. (1989b), arguing that low density metropolitan areas with their decentralized employment centers facilitate shorter work trips and high density areas are subject to congestion. The relationships between residential density and travel parameters (travel time, distance, speed) are re-examined here by looking at a cross-section of cities in the United States. If metropolitan density is positively associated with high commuting times, it must be the density which is a consequence of trying to reduce otherwise higher interaction costs (in times past) in a city, which without increasing density would spread over a larger space, and not the other way around. Density, after controlling for city size, would be associated with shorter distances and slower speeds, but since density and city size are highly correlated both variables cannot be used in the regressions and still get meaningful results, a priori the results will be uncertain.

Local residential density. Local residential density is the best available measure in the 1990 NPTS data set of relative location of the household within the metropolitan region. As noted above, there are theoretical reasons that 
density and non-auto mode shares should be associated, and possibly density and trip rates due to opportunities for trip chaining.

TABLE 1. TRANSPORTATION AND LAND USE VARIABLES FOR U.S. METROPOLITAN AREAS

\begin{tabular}{|c|c|c|c|c|c|c|c|}
\hline $\begin{array}{l}\text { Metropolitan } \\
\text { Area } \\
\text { (by central city) }\end{array}$ & $\begin{array}{l}1990 \\
\text { Pop. } \\
\text { (millions) }\end{array}$ & $\begin{array}{c}90-' 80 \\
\text { Change } \\
\text { in Pop. } \\
(\%)\end{array}$ & $\begin{array}{c}1980 \\
\text { Urban } \\
\text { Density } \\
\text { (PPSM) }\end{array}$ & $\begin{array}{c}1980 \\
\text { Metro } \\
\text { Density } \\
\text { (PPSM) }\end{array}$ & $\begin{array}{c}\text { Mean } \\
\text { Total } \\
\text { Trips } \\
\text { perPerson } p\end{array}$ & $\begin{array}{l}\text { Mean } \\
\text { Work } \\
\text { Trips } \\
\text { er Person }\end{array}$ & $\begin{array}{c}\text { Mean } \\
\text { Vehicles } \\
\text { per } \\
\text { H'sh'd }\end{array}$ \\
\hline Rochester, NY & 1 & $3 \%$ & 3015 & 330 & 3.87 & 0.87 & 2.39 \\
\hline Salt Lake City, UT & 1.1 & $18 \%$ & 2225 & 109 & 3.96 & 0.69 & 2.34 \\
\hline Orlando, FL & 1.1 & $53 \%$ & 1850 & 274 & 3.75 & 0.97 & 2.56 \\
\hline Hartford, CT & 1.1 & $7 \%$ & 2452 & 703 & 3.87 & 0.80 & 2.18 \\
\hline Providence, RI & 1.1 & $5 \%$ & 2824 & 1127 & 3.97 & 0.72 & 2.29 \\
\hline Charlotte, NC & 1.2 & $20 \%$ & 1846 & 418 & 4.03 & 1.04 & 2.36 \\
\hline Buffalo, NY & 1.2 & $-4 \%$ & 3768 & 790 & 3.46 & 0.71 & 2.25 \\
\hline New Orleans, LA & 1.2 & $-1 \%$ & 4688 & 622 & 3.98 & 0.83 & 1.75 \\
\hline Indianapolis, IN & 1.2 & $7 \%$ & 1932 & 379 & 3.92 & 0.83 & 1.99 \\
\hline San Antonio, TX & 1.3 & $21 \%$ & 2669 & 426 & 3.88 & 0.77 & 1.90 \\
\hline Columbus, $\mathrm{OH}$ & 1.4 & $11 \%$ & 2733 & 444 & 4.03 & 0.72 & 2.06 \\
\hline Norfolk, VA & 1.4 & $20 \%$ & 1844 & 600 & 3.94 & 0.90 & 1.88 \\
\hline Portland, OR & 1.5 & $14 \%$ & 2940 & 504 & 3.91 & 0.67 & 2.45 \\
\hline Sacramento, CA & 1.5 & $35 \%$ & 2864 & 298 & 3.84 & 0.61 & 2.30 \\
\hline Kansas City, MO & 1.6 & $9 \%$ & 1864 & 398 & 4.24 & 1.01 & 1.97 \\
\hline Milwaukee, WI & 1.6 & $2 \%$ & 2433 & 456 & 4.04 & 0.80 & 1.80 \\
\hline Cincinnati, $\mathrm{OH}$ & 1.7 & $5 \%$ & 2675 & 636 & 3.53 & 0.80 & 2.22 \\
\hline Denver, CO & 1.8 & $14 \%$ & 3080 & 349 & 3.85 & 0.86 & 2.22 \\
\hline Tampa/St.Pete., FL & L $\quad 2.1$ & $28 \%$ & 2600 & 758 & 4.18 & 0.76 & 1.79 \\
\hline Phoenix, AZ & 2.1 & $41 \%$ & 2199 & 165 & 4.18 & 0.67 & 2.11 \\
\hline Pittsburgh, PA & 2.2 & $-7 \%$ & 2539 & 741 & 3.70 & 0.74 & 1.94 \\
\hline Baltimore, MD & 2.4 & $8 \%$ & 3359 & 467 & 3.37 & 0.90 & 2.03 \\
\hline St. Louis, MO & 2.4 & $3 \%$ & 3096 & 474 & 4.04 & 0.73 & 2.12 \\
\hline Minneapolis, MN & 2.5 & $15 \%$ & 1824 & 459 & 3.92 & 0.75 & 2.10 \\
\hline San Diego, CA & 2.5 & $34 \%$ & 2789 & 442 & 4.18 & 0.74 & 2.28 \\
\hline Seattle, WA & 2.6 & $22 \%$ & 2869 & 354 & 3.66 & 0.80 & 2.29 \\
\hline Cleveland, $\mathrm{OH}$ & 2.8 & $-3 \%$ & 2786 & 971 & 4.11 & 0.79 & 2.23 \\
\hline Atlanta, $\mathrm{GA}$ & 2.8 & $33 \%$ & 1783 & 467 & 3.80 & 0.92 & 2.24 \\
\hline Miami, FL & 3.2 & $21 \%$ & 4730 & 832 & 3.74 & 0.72 & 1.85 \\
\hline Houston, TX & 3.7 & $20 \%$ & 2300 & 434 & 3.99 & 0.72 & 2.26 \\
\hline Dallas/Ft.Worth, TX & $\times \quad 3.9$ & $33 \%$ & 1915 & 357 & 4.18 & 0.82 & 2.30 \\
\hline Washington, DC & 3.9 & $21 \%$ & 3424 & 1089 & 3.94 & 0.90 & 2.05 \\
\hline Boston, MA & 4.2 & $5 \%$ & 3126 & 2232 & 4.00 & 0.88 & 2.06 \\
\hline Detroit, MI & 4.7 & $-2 \%$ & 3649 & 993 & 4.16 & 0.78 & 2.22 \\
\hline Philadelphia, PA & 5.9 & $4 \%$ & 4052 & 1144 & 3.81 & 0.81 & 2.01 \\
\hline San Francisco, CA & 6.3 & $16 \%$ & 4008 & 744 & 3.85 & 0.70 & 2.19 \\
\hline Chicago, IL & 8.1 & $2 \%$ & 4526 & 1601 & 3.79 & 0.77 & 2.04 \\
\hline Los Angeles, CA & 14.5 & $26 \%$ & 5189 & 338 & 3.77 & 0.78 & 2.17 \\
\hline New York, NY & 18.1 & $3 \%$ & 5552 & 3341 & 3.74 & 0.83 & 1.90 \\
\hline \multicolumn{4}{|c|}{ R-Squared (Independent Variable $=$ POPg0) 0.49} & 0.42 & 0.02 & & \\
\hline
\end{tabular}

source: (a) - 1980 U.S. Census, 1990 U.S. Census

(b) - 1990/91 Nationwide Personal Transportation Survey 
TABLE 1 (CONTD)

\begin{tabular}{|c|c|c|c|c|c|}
\hline \multirow[b]{2}{*}{$\begin{array}{l}\text { Metropolitan } \\
\text { Area } \\
\text { (by central city) }\end{array}$} & \multirow[b]{2}{*}{$\begin{array}{c}\text { Mean } \\
\text { Time } \\
\text { (minutes) }\end{array}$} & \multicolumn{3}{|c|}{ Commuting Variables } & \multirow[b]{2}{*}{$\begin{array}{r}\text { Sample } \\
\text { Size } \\
\text { (persons) }\end{array}$} \\
\hline & & $\begin{array}{c}\text { Mean } \\
\text { Distance } \\
\text { (miles) } \\
\end{array}$ & $\begin{array}{l}\text { Mean } \\
\text { Speed } \\
(\mathrm{mph})\end{array}$ & $\begin{array}{c}\text { Automobile } \\
\text { Mode } \\
\text { Share }\end{array}$ & \\
\hline Rochester, NY & 20.2 & 12.3 & 34.5 & 0.99 & 129 \\
\hline Salt Lake City, UT & 15.9 & 7.0 & 25.9 & 0.97 & 102 \\
\hline Orlando, FL & 20.6 & 9.4 & 26.9 & 1.00 & 129 \\
\hline Hartford, CT & 20.1 & 11.0 & 30.9 & 0.96 & 1003 \\
\hline Providence, RI & 19.4 & 11.6 & 35.1 & 0.96 & 148 \\
\hline Charlotte, NC & 19.6 & 10.1 & 31.6 & 0.97 & 149 \\
\hline Buffalo, NY & 20.1 & 11.3 & 33.3 & 1.00 & 112 \\
\hline New Orleans, LA & 20.8 & 10.4 & 29.1 & 0.95 & 126 \\
\hline Indianapolis, IN & 18.1 & 9.8 & 31.2 & 0.98 & 1692 \\
\hline San Antonio, TX & 16.7 & 10.7 & 36.1 & 1.00 & 154 \\
\hline Columbus, $\mathrm{OH}$ & 20.7 & 9.9 & 29.1 & 0.93 & 197 \\
\hline Norfolk, VA & 19.5 & 9.8 & 31.1 & 0.94 & 171 \\
\hline Portland, OR & 20.7 & 10.7 & 30.0 & 0.96 & 198 \\
\hline Sacramento, CA & 23.7 & 15.4 & 34.5 & 1.00 & 183 \\
\hline Kansas City, MO & 18.8 & 11.6 & 35.5 & 0.97 & 259 \\
\hline Milwaukee, WI & 19.1 & 9.9 & 30.9 & 0.91 & 222 \\
\hline Cincinnati, $\mathrm{OH}$ & 20.1 & 11.7 & 34.5 & 1.00 & 290 \\
\hline Denver, CO & 20.2 & 10.6 & 31.4 & 0.94 & 262 \\
\hline Tampa/St.Pete., FL & 17.5 & 7.4 & 26.5 & 0.97 & 254 \\
\hline Phoenix, AZ & 21.2 & 11.5 & 30.7 & 0.98 & 287 \\
\hline Pittsburgh, PA & 19.0 & 8.8 & 28.0 & 0.95 & 308 \\
\hline Baltimore, MD & 26.2 & 14.8 & 32.8 & 0.91 & 312 \\
\hline St. Louis, MO & 19.9 & 10.4 & 31.1 & 0.96 & 361 \\
\hline Minneapolis, MN & 20.4 & 10.8 & 30.9 & 0.95 & 307 \\
\hline San Diego, CA & 20.5 & 12.7 & 33.5 & 0.96 & 360 \\
\hline Seattle, WA & 26.3 & 11.6 & 29.2 & 0.96 & 318 \\
\hline Cleveland, $\mathrm{OH}$ & 20.7 & 10.8 & 28.5 & 0.96 & 354 \\
\hline Atlanta, GA & 21.9 & 12.7 & 33.2 & 0.96 & 400 \\
\hline Miami, FL & 22.6 & 10.6 & 30.1 & 0.97 & 297 \\
\hline Houston, TX & 20.9 & 11.4 & 31.2 & 0.98 & 489 \\
\hline Dallas/Ft. Worth, TX & 19.2 & 11.1 & 34.1 & 0.99 & 485 \\
\hline Washington, DC & 28.9 & 13.5 & 28.0 & 0.92 & 590 \\
\hline Boston, MA & 21.2 & 11.2 & 28.4 & 0.90 & 373 \\
\hline Detroit, MI & 21.5 & 12.4 & 34.5 & 0.99 & 597 \\
\hline Philadelphia, PA & 22.7 & 12.3 & 30.5 & 0.92 & 721 \\
\hline San Francisco, CA & 23.0 & 11.4 & 29.7 & 0.89 & 698 \\
\hline Chicago, IL & 25.5 & 12.5 & 27.7 & 0.90 & 975 \\
\hline Los Angeles, CA & 24.2 & 13.4 & 31.7 & 0.96 & 1581 \\
\hline New York, NY & 26.7 & 12.7 & 27.9 & 0.81 & 4479 \\
\hline R-Squared & 0.38 & 0.18 & 0.04 & 0.35 & 20072 \\
\hline
\end{tabular}

(Independent Variable $=$ POP90) 
However there is no theoretical reason that density per se should have any effect on journey-to-work travel time. The findings indicate that, as a determinant of travel time, the variable representing local residential density measures most importantly congestion and distance from the center(s), rather than density itself.

First, the travel time between places depends on the speed of the transportation network, a function of traffic flow, which is strongly correlated with density. At uncongested levels of traffic, a one percent increase in traffic flow on a section of roadway increases travel time by far less than one percent; at congested levels, a one percent increase in flow increases time by far more than one percent.

Second, intensity of use tends to decline with distance from the city's center(s), resulting in shorter trips in high density areas. However the relationship between density and distance from the center is not fixed. Over the past century, due to congestion costs coupled with the increasing accessibility in lower density areas associated with the new technologies of the automobile and freeway, the CBD(central business district)-density gradient has been shown to be declining in U.S. cities (Mills 1972; Heikkila et al. 1989). The emergence of polycentric cities further reflects the declining relative importance of the single center in a city, and suggests an increasing disparity between density and distance from the dominant regional center (CBD), though not necessarily from secondary suburban centers (Giuliano and Small 1991; Gordon et al. 1986; Greene 1980; McDonald 1987; and McDonald and Prather 1994).

Table 2 shows that by auto, home-to-work travel times are fairly constant for densities below 10,000 persons per square mile (ppsm); however, travel times increase at densities above $10,000 \mathrm{ppsm}$. Mean time by auto increases from 20 minutes at densities below 10,000 to 38 minutes in areas above 50,000 ppsm. By transit, home-to-work travel times remain approximately 50 minutes below 5,000 ppsm; 40 minutes between 5,000 and 50,000 ppsm; and about 32 minutes above $50,000 \mathrm{ppsm}$. A comparison of auto and transit can be seen with the ratio of transit time to auto time. At values greater than 1 , transit time exceeds auto time. This variable drops from 2.9 (transit trips taking about three times as long as auto trips) at densities less than $4,000 \mathrm{ppsm}$ to 0.9 at densities greater than $50,000 \mathrm{ppsm}$, beyond which transit mode share exceeds auto mode share. Distance and speed both decline with increased density.

Two standard hypotheses concerning density are tested. The first is that density is negatively associated with trip speed for all modes of travel. Density and congestion typically go hand in hand, so this relationship is expected. The second hypothesis is that density is negatively associated with commuting distance. As noted before, density declines with distance from the center of the region. Also city centers typically have high job-to-housing ratios. Therefore, due to high job accessibility in high density residential neighborhoods 
the second hypothesis should be borne out in the data. Both hypotheses will be confirmed if a declining coefficient is found on the density variables in the distance and speed regressions.

The third hypothesis should concern travel time. But because density and speed are both expected to be negatively related to density, the effect on commuting time depends on the magnitude of the other relationships. After examining the data, higher densities should reduce automobile travel time up to a point (between 7,500 and 10,000 ppsm), and above that level, auto times will rise because the speed reduction outweighs the density reduction. Because that density class is suppressed, in the automobile regression the sign on the population density variables is expected to be found positive in all cases, and rising as the density class is farther from the suppressed class. A "U" shaped curve of density on the $\mathrm{X}$ axis and travel time on the $\mathrm{Y}$ axis, with the base of the " $U$ " being the suppressed density class, is expected.

Centricity. Land use is not evenly distributed; rather centers, by definition, have more opportunities per unit area than does the periphery. If cities increased in population without any change in density, they would extend farther in space and commutes would become longer. To reduce overall interaction costs (journey-to-work, non-work, and firm-to-firm) it becomes desirable to build at higher densities in certain locations, which then become the regional center(s).

Theory suggests, that after controlling for city size (or metropolitan density), the more monocentric city will have higher commuting times for automobile commuters, since the primary reason for polycentricity is to contain or reduce commuting costs. On the other hand, since polycentricity (like density discussed above) is a response to already high commuting times, the statistical association may come in the other direction. It is important to recognize that cause and effect here run in both directions as individuals and firms mutually co-locate in response to congestion costs, and thus reshape those costs. Two key issues are the degree of concentration or clustering both within and outside the central city and the distribution of employment relative to population.

However, since there is no measure of the location of individual's workplace in the NPTS data set, surrogates are used. Gordon et al. (1989b) use the proportion of metropolitan employment located in the MSA's central city as an explanatory factor for travel time to work and find them to be positively associated. That measure indicates the degree of monocentricity, but unfortunately relies on central city boundaries which are politically rather than economically defined.

The measure (EDGECITY) looks at the number of suburban activity centers in the metropolitan area (Edge Cities in the terminology of Garreau (1991)) as a measure of polycentricity, loosely capturing the amount of clustering of jobs 
outside the central city. Garreau's list is used, which he obtained using the five part definition of: five million square feet of leasable office space, six hundred thousand square feet of retail, an importer of workers to fill jobs, a perception as a mixed use destination, and a history that 30 years before it was not such a center. Clearly this is associated with city size, though non-linearly; only when a city becomes sufficiently large is it worthwhile for firms to lose some firm-to-firm agglomeration economies to achieve an advantage in the labor market.

Growth rate. The rate at which opportunities change may also influence travel times. Individuals typically only relocate a job or home every few years; they cannot respond instantly to faster growth and changes in opportunities. Because relocation costs are not zero, a changing city size, indicative of the absence of equilibrium, may impact travel times. A variable (GROWRATE) is used to express the percentage population growth between 1980 and 1990. A growing city may provide greater opportunities for households and economic establishments to relocate, resulting in shorter time and distance commutes. Alternatively, a growing city may have difficulty providing adequate transportation infrastructure in a timely fashion (hence the rise of growth management in many fast growing suburbs in the United States) resulting in longer commutes. In numerous studies it has been shown that total travel has been growing faster than transportation network capacity. Insufficient capacity may lead to higher than average travel times. Growth may also be a surrogate for the sunbelt urban form more than change within a city, therefore, this variable needs to be treated with caution.

Transportation technology. Commuting time is a function of the available technology. A higher speed technology, ceteris paribus, will lead to shorter duration commutes. But since duration also depends on distance, and the higher speeds can be used to extend commuting range, the impacts of technology will have to be determined empirically. There is also the compounding factor of modal investment strategies. Some cities have chosen to invest in heavy rail systems, often at the expense of highways. This should increase the travel time of highway commuters.

Transportation investments vary between cities; typically, newer cities have more freeways, older cities have more mass transit. A dummy variable (RAILCITY), takes the value 1 for those cities with a heavy rail system (Atlanta, Baltimore, Boston, Chicago, Cleveland, Miami, New York, Philadelphia, San Francisco, Washington DC) and 0 otherwise. Presence of a rail system is an important variable explaining the organization of city structure. Typically, cities with rail have a denser central area and higher densities around stations. A city, by choosing to invest its infrastructure dollars in a rail system, may preclude that money from being spent on highways, thereby leading to lower speeds and possibly higher travel times by auto.' Further research could treat rail mileage (by type of facility, e.g. light rail or heavy rail) as a measure of transit availability. The hypothesis tested is 
that presence of heavy rail will be positively associated with distance and speed for transit users and negatively associated with speed for auto commuters.

As with land use patterns, transportation networks vary both between and within cities. Because of increased traffic density, speeds on links in areas of higher density near the "center" tend to be lower than speeds on links at the periphery. The variable FREECITY ranges from 0 to 1 , and represents the total share of automobile travel (both work and non-work trips) in a city that takes place on freeways or other limited access roadways. This variable was computed from the NPTS, which asked a subsample in each city specific questions on the mileage of each trip on one of four classes of roadway. The hypothesis is that freeway-orientation will be positively associated with auto speeds, and thus will have trips of longer distances to take advantage of them.

Income. Income is expressed as the ratio of household income for an individual to median metropolitan income in his or her city (INCRATIO). By controlling for metropolitan income levels it is hoped to alleviate some of the problems associated with comparing income levels in different cities. Gordon et al. (1989b) argue that high income households have more choice in residential location, implying that these households can choose good housing if it is close to the workplace. Similarly, high income households may place a higher dollar value on time and be more willing to substitute money for commuting time. Both factors may lead to shorter travel times in the polycentric urban model. However, in the monocentric city, travel distances have typically been found to be longer for high income persons, who more often live in the suburbs.

The degree to which income is related to travel time is thus a function of urban structure and the extent of decentralization. Results obtained using median income of a city in an aggregate analysis mask different costs of living found in different cities, and may be different than those obtained using relative household income at the individual level. Higher income is also related to increased professional specialization, which should result in longer distance work trips. However, household income also masks the relationship of personal income on travel behavior in two-worker households. If a greater proportion of higher income households live in the suburbs, while central city office jobs are higher paying, longer distance and time commutes are expected to result, giving higher speeds obtained on the longer suburban portion of the trip.

Gender and age. Gender and age are considered in the individual regressions. The variable reflecting gender (MALE) is expressed as a binary variable taking the value 1 if the individual is male and 0 if female or not reported. AGExx-yy is a series of dummy variables representing cohorts from $16-20,20-30,30-40,40-50,50-60,60-70$ and $70+$, with the cohort representing 
30-40 suppressed. (In the city by city regressions, because of smaller sample sizes, two cohorts were used, defined by a dummy variable ADULT if the individual was between the ages of 18 and 65.) Peters and MacDonald's 1994 review of the literature shows that men commute longer than women, with various hypotheses put forward relating to the relative importance of the home and nature of the job. Working age adults are also expected to have longer commutes than those below 20 or above 65 , as full-time jobs are typically farther afield than part-time.

\section{Data}

The 1990/91 Nationwide Personal Transportation Survey, used in this study, consists of 21,000 household interviews and 47,000 persons making almost 150,000 trips. Additional information about the site of the interviewee (such as residential density) was added after the interview. The survey collected data on household demographics, income, vehicle availability, all trips made on the survey day, long trips made over a two week period, and traffic accidents within the past five years. Trip characteristics included departure time, distance and duration of the trip, trip purpose and mode, and the vehicle used.

The key land use variables in this study are the population density of the residential zip code from the NPTS data set and a number of other variables obtained from the Census, including metropolitan size, urbanized and metropolitan population density in 1980 and 1990 (U.S. Dept. of Transportation 1990; U.S. Bureau of Census 1984, 1991). Some discussion of the measure of local population density measure used here is warranted. Households were asked to provide their home postal area, or zip code, as a geographic reference. The zip code was then matched to an external data set containing population and area estimates. Population per square mile (ppsm) was calculated for each zip code area and collapsed to the classes shown in the tables presented in this paper. It should be noted that population density thus computed may vary widely between zip codes because of the inclusion of undeveloped land in the area estimates. Lower density areas are expected to have more undeveloped land included in the area measurement of zip code than high density areas. While it would be desirable to have estimates of developed land density by land use type at a local level, this data was unavailable. However, the available information is still useful for understanding the broader relationship between density and travel patterns. National travel surveys conducted in 1969, 1977, and 1983 did not record population density, precluding this type of analysis. In addition, as discussed above, it is noted that density computed this way likely acts as a surrogate for distance from the center of the metropolitan region. While the monocentric urban form is becoming polycentric, density still tends to decline with distance 
from the center. It was not possible to separate the effects of density and distance in this database, as only the residential density variable was provided and there was no similar variable indicating distance from the center of the region, and so they are treated together.

\section{Results}

Four sets of regressions were performed to test the hypotheses in various ways. These are shown in a number of tables which are addressed one by one in the following subsections. Table 3 records the regressions on time, speed, and distance of 8651 individual automobile commuters across the country; Table 4 looks at 627 individual transit commuters; Charts 1, 2, and 3 summarize the regressions of individual automobile commuters in each of 39 cities; and Table 5 looks at transit commuters in New York.

In general these regressions, because they are performed using as observations the behavior of individuals, have a lower R-square than would a regression against aggregates (such as mean metropolitan commuting time, distance or speed). While it may be difficult to predict the behavior of individuals, it appears that many of the tested explanatory variables are statistically significant. Nevertheless, it is given that there are clearly many variables which were not included (because of lack of availability), or have been aggregated due to small sample sizes, which would more completely explain individual choices, including specifics about residential location, their profession, the patterns of job opportunities relating to that profession and the like. All such research needs to be treated with caution and analyzed from many perspectives with alternative data sets.

Automobile commuters: Nationally. Table 3 shows the regression of density and other explanatory variables with travel time, distance, and speed for automobile commuters. In this regression local residential density is defined by a series of dummy [1,0] variables (PD0-99 to PD50000+) indicating residence in a zip code in the respective density class, as shown in Table 2 . Of these classes, PD7500-9999 is suppressed to more clearly demonstrate the automobile travel time hypothesis. The results for trip distance and speed are as hypothesized: higher density areas have slower speeds and shorter distances. As expected the relationship between density and travel time requires some further discussion: generally travel time is positively associated with density above 10,000 ppsm and negatively associated with density below 7,500 ppsm. Densities above $10,000 \mathrm{ppsm}$, and particularly over 50,000 ppsm, are observed primarily in older central cities, for instance New York (discussed further in a later section), where diseconomies resulting from congestion may exceed the advantage of higher accessibility. Below the 7,500 ppsm threshold, higher 


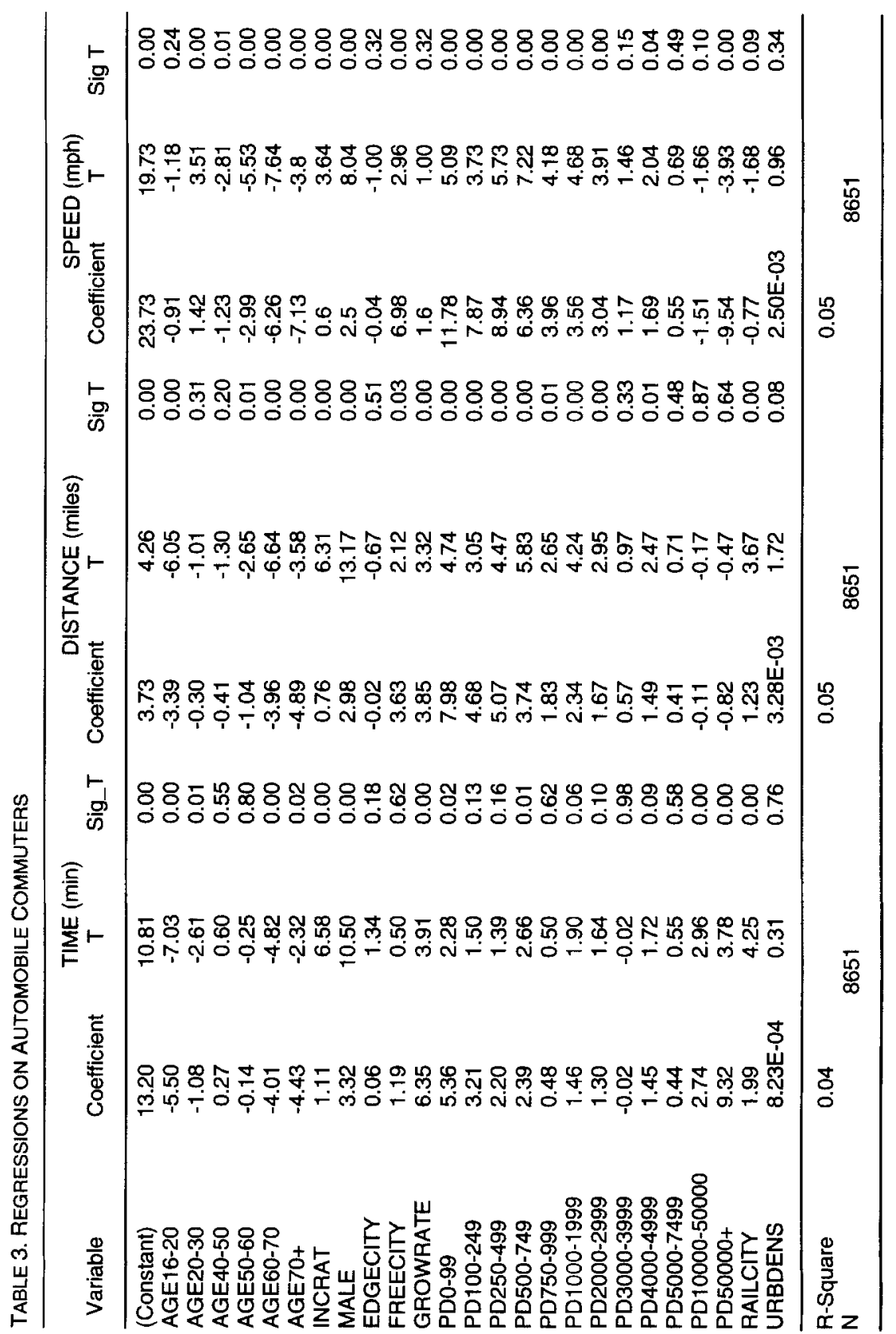


residential density areas offer the advantage of better accessibility without as severe a penalty in slower speeds, resulting in lower commuting time.

Urbanized area population density is positively associated with distance and not statistically significant against time or speed. This tends to support the hypothesis that metropolitan density is operating as a surrogate for city size. The number of edge cities, representing the degree of polycentricity was not statistically significant. The rate of growth, a measure of urban disequilibrium, was positively associated with travel time and distance, though not speed. This corroborates the idea that high rates of change coupled with relocation costs may prevent individuals from achieving their preferred bundle of housing and travel choices.

The presence of heavy rail is positively associated with auto commuting time and distance, and negatively associated with speed. The interesting part of this is not distance or time, whose positive signs are in part a function of some autocorrelation between the presence of rail and size of the city, but speed, which is lower for auto commuters in cities with rail infrastructure, suggesting a possible investment effect. The proportion of travel on freeways is positively associated with both distance and speed, and not associated with time, suggesting the higher speeds are used to make longer distance commutes, but not so far as to increase durations.

The socio-economic and demographic hypotheses were corroborated. The regressions show that, for auto commuters, having a relatively high income, being a male, and being a middle-aged adult was positively associated with travel distance, speed, and time. The longest times were found for adults in the suppressed category (age 30-40) and the adjacent 40-50 year old category, as all others were negative relative to the suppressed category. Distances were longest for the 30-40 year old group, while speeds were highest for the 20-30 year olds.

Transit commuters: Nationally. Table 4 shows the regression for transit users across the country. While in the previous section each density class could be used as an independent variable, because of the smaller sample of transit commuters, here the density variable was aggregated to attain meaningful results. Two continuous density variables are defined: DENSLOW was set equal to the density for areas below $10,000 \mathrm{ppsm}$ and was set equal to zero for areas at or above 10,000 ppsm; and DENSHIGH was set equal to the density at values of $10,000 \mathrm{ppsm}$ and above, and was set equal to zero for areas below $10,000 \mathrm{ppsm}$. The $10,000 \mathrm{ppsm}$ cut-off point was identified after a careful examination of the data, and reflects the findings from the previous section. Although the exact inflection point of the travel time vs. density relationship probably ranges somewhere between 7500 and $10,000 \mathrm{ppsm}$; the data classes recorded with the NPTS data prevent a finer analysis. 


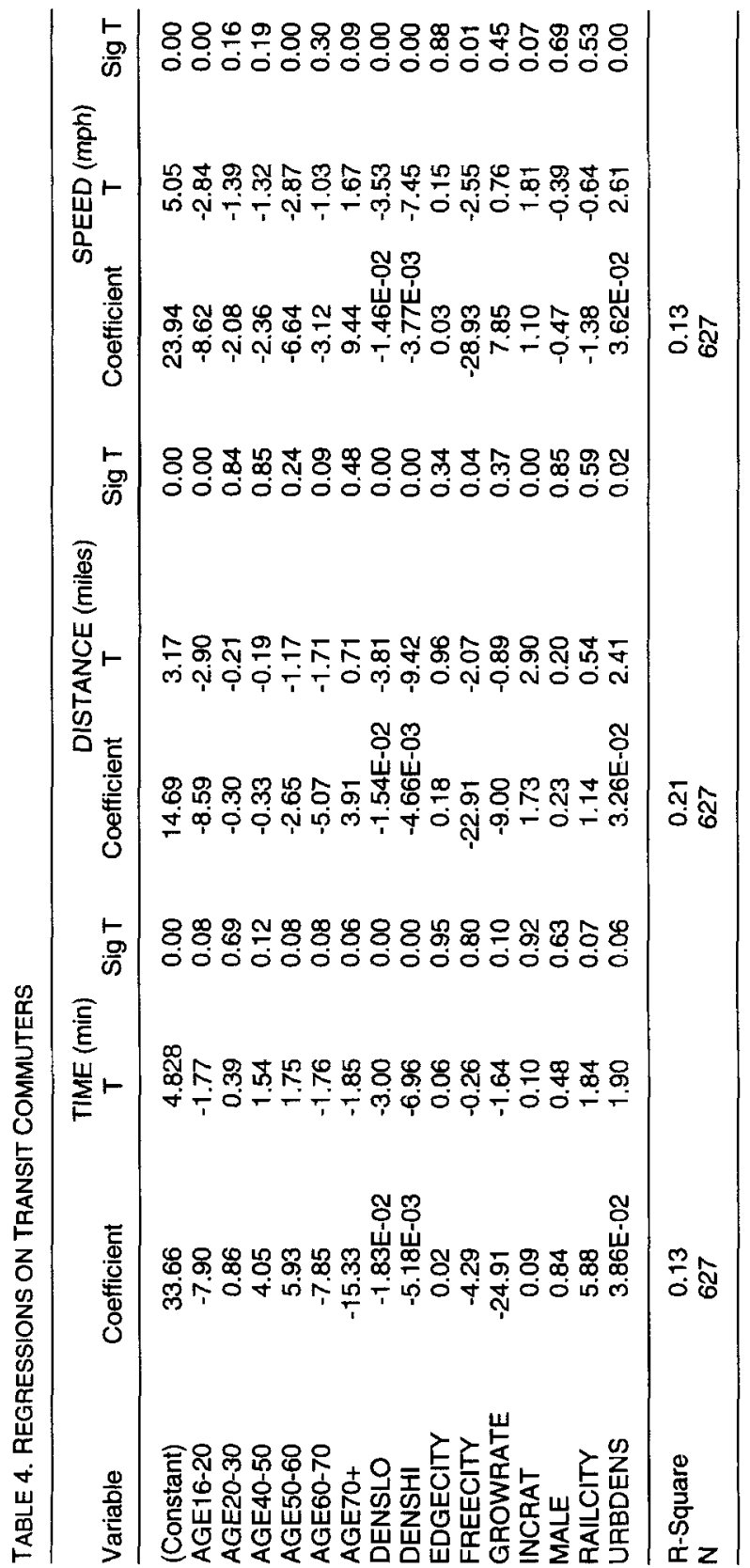


In contrast to auto commuters, transit users display a negative relationship between travel time and density both above and below the 10,000 ppsm density threshold, though the slope changes. Density is positively related to metropolitan population, and bigger cities may be better served by transit facilities. Declining travel times by transit and increasing travel times by auto as density rises above $10,000 \mathrm{ppsm}$ result in higher transit mode shares, as shown in Table 2.

The metropolitan density (URBDENS), principally a surrogate for city size, is positively associated with time, distance, and speed, possibly because of higher rail transit use. As with autos, the number of edge cities was not statistically significant. However, unlike autos the growth rate was not statistically significant, perhaps because of fairly low transit use in cities with high growth rates (typically sunbelt cities), and particularly low transit use in the fastest growing (suburban) areas. Population growth probably needs to be analyzed with changes in travel time using a longitudinal survey to more fully understand its influence.

For transit commuters, time was positively associated with presence of heavy rail, but distance and speed was not significant. In further analyses of transit, the impacts of bus and of rail should be isolated. Freeway use is negatively related to speed and distance, and again is not related to travel time. Freeways may be associated with bus use as opposed to rail use for transit commuters, and again reflect the influence of investment patterns and history on commuting behavior.

Income was associated with higher distances and speed, but the results for time were not statistically significant. The question of whether high income persons who live and work in the suburbs have shorter commutes than similarly situated lower income persons remains outstanding. For transit trips, adulthood has its expected influence while, unlike for auto trips, gender is not statistically significant.

Automobile commuters: City by city. The NPTS database offers the possibility of analyzing the travel time relationship for specific cities. Several cities augmented the sample size by contributing additional resources. Figure 1 shows residential density vs. travel time (by motorized modes) for four cities (New York, Los Angeles, Chicago, and Indianapolis). Figures 2 and 3 show density vs. distance and speed respectively. Travel time changes marginally with density for each of the cities except New York. Indianapolis, the only city shown below 2 million population, has travel times one-third lower than the other three cities (each above 8 million). Because sample sizes are low in density classes above 10,000 ppsm, excepting New York, the relationship of high densities being positively associated with travel time (discussed below) might only be found in cities of the size and density of New York. This issue will be investigated further. 


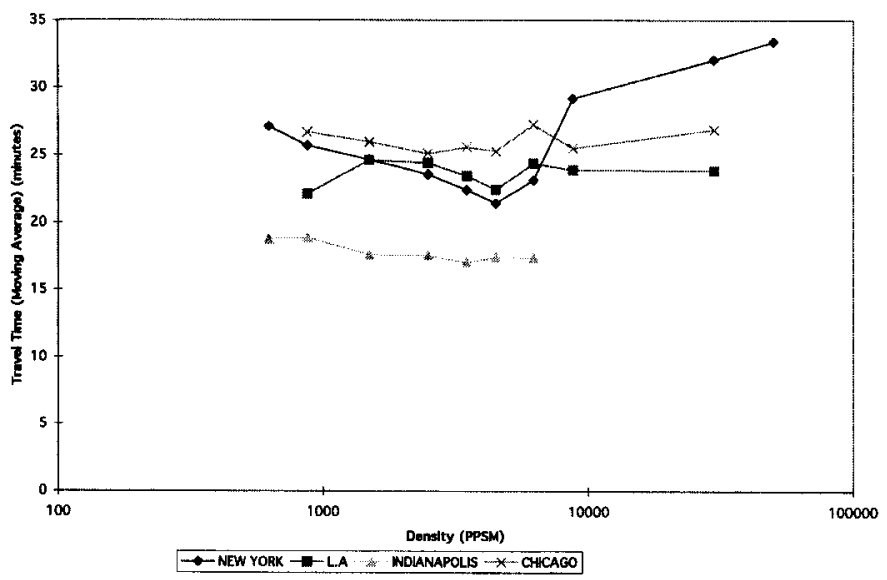

FIGURE 1. TRAVEL TIME VS. DENSITY

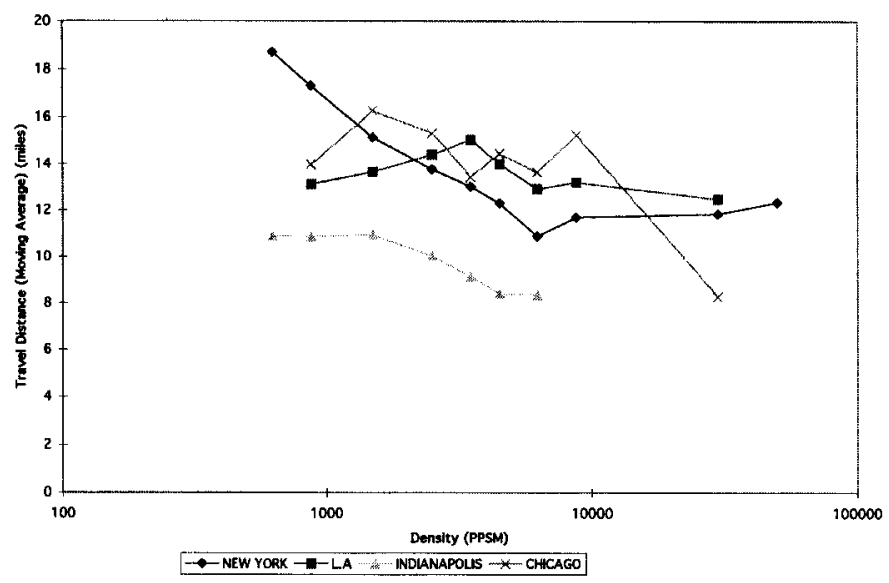

Figure 2. TRaVel Distance VS. Density

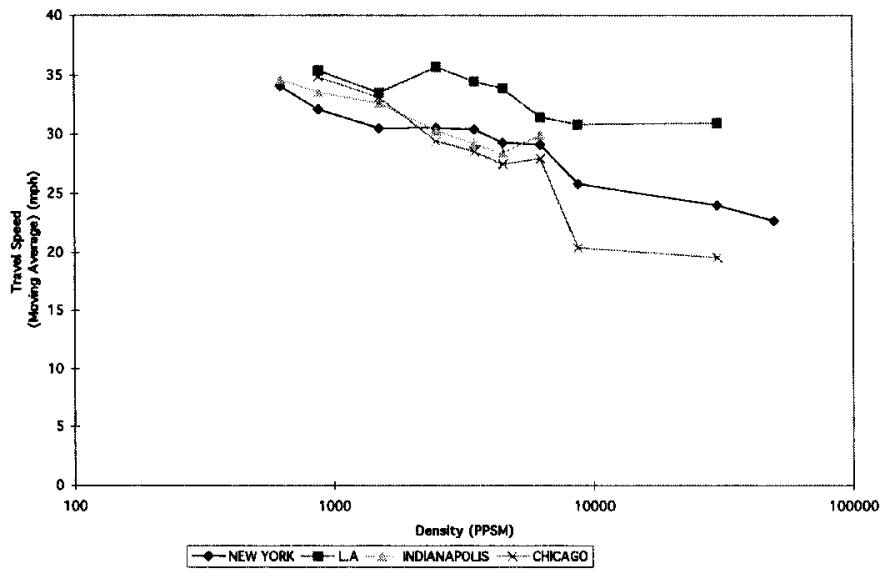

FiguRE 3. TRAVEL SPEED VS. DENSITY 
The previous section reviewed both inter- and intra- metropolitan variations in travel time, speed, and distance using national data. However, the inter-metropolitan variation can be eliminated by performing regressions on individual cities. Regressions were conducted to predict travel speed, distance, and time for automobile commuters in each of 38 specific cities using demographic (age, gender, income ratio) and density variables as independent factors. As in the transit section, because of the small samples in each density class in individual cities, the aggregate DENSLOW and DENSHIGH variables were used. The key findings of the regressions are summarized in Charts 1-3, which show the number of cities in which the hypotheses are corroborated, and the full tables are available upon request.

CHARTS FOR CITY BY CITY REGRESSIONS ON AUTOMOBILE COMMUTERS:

Chart 1: Summary of Results for Automobile Commuting Speed

\begin{tabular}{lccccc}
\hline Variable & Hypothesis & $\begin{array}{c}\text { Number of } \\
\text { Cities } \\
\text { Available }\end{array}$ & $\begin{array}{c}\text { Positive \& } \\
\text { Significant }\end{array}$ & $\begin{array}{c}\text { Negative \& } \\
\text { Significant }\end{array}$ & $\begin{array}{c}\text { Not } \\
\text { Significant }\end{array}$ \\
\hline ADULT & + & 31 & 9 & 2 & 20 \\
DENSHI & - & 18 & 2 & 10 & 6 \\
DENSLOW & - & 38 & 2 & 19 & 17 \\
MALE & + & 38 & 8 & 1 & 29 \\
INCRAT & + & 38 & 8 & 3 & 27 \\
\hline
\end{tabular}

Chart 2: Summary of Results for Automobile Commuting Distance

\begin{tabular}{lccccc} 
Variable & Hypothesis & $\begin{array}{c}\text { Number of } \\
\text { Cities } \\
\text { Available }\end{array}$ & $\begin{array}{c}\text { Positive \& } \\
\text { Significant }\end{array}$ & $\begin{array}{c}\text { Negative \& } \\
\text { Significant }\end{array}$ & $\begin{array}{c}\text { Not } \\
\text { Significant }\end{array}$ \\
\cline { 1 - 4 } ADULT & + & 31 & 9 & 2 & 20 \\
DENSHI & - & 18 & 0 & 6 & 12 \\
DENSLOW & - & 38 & 2 & 17 & 19 \\
MALE & + & 38 & 20 & 1 & 17 \\
INCRAT & + & 38 & $\mathbf{1 4}$ & 4 & 20 \\
\hline
\end{tabular}

Chart 3. Summary of Results for Automobile Commuting Time

\begin{tabular}{lccccc} 
Variable & Hypothesis & $\begin{array}{c}\text { Number of } \\
\text { Cities } \\
\text { Available }\end{array}$ & $\begin{array}{c}\text { Positive \& } \\
\text { Significant }\end{array}$ & $\begin{array}{c}\text { Negative \& } \\
\text { Significant }\end{array}$ & $\begin{array}{c}\text { Not } \\
\text { Significant }\end{array}$ \\
\hline ADULT & + & 31 & 10 & 1 & 20 \\
DENSHI & $+(?)$ & 18 & 2 & 3 & 11 \\
DENSLOW & $-(?)$ & 38 & 3 & 7 & 28 \\
MALE & + & 38 & 17 & 2 & 19 \\
INCRAT & + & 38 & 12 & 5 & 11 \\
\hline
\end{tabular}


The hypotheses for speed, time, and distance are shown in Charts 1,2, and 3 , respectively where a "+" or "-" reflect whether the relationships are expected to be positive or negative. Then the number of cities where the results are positive and significant at the 90 percent level or better, negative and significant, and not significant are given.

The general hypotheses for this section are confirmation of the results shown in the previous section for the country as a whole. By and large, these are corroborated, as seen in Chart 1. Residential density is clearly negatively associated with speed in most cities at both high and low density levels. The two anomalies (in both low and high density categories) are Providence, Rhode Island and Columbus, Ohio, two of the smallest cities in the analysis, both with small sample sizes.

The results for automobile commuting distance are shown in Chart 2. Density is negatively correlated with commuting distance in almost all cases where significant (Philadelphia and Buffalo excepted for low density areas). The national results are thus in general corroborated.

Chart 3 shows the summary of the regressions to predict automobile commuting time in each of 38 cities. The majority of the cities showed no significant relationship between commuting time and density, at either low or high density, suggesting that speed and distance are mostly offsetting. Where it was significant, the tendency was the higher the density the lower the time for low density areas, corroborating the national results. For high density areas, only 5 of 18 cases were significant, and they were split 3 negative, 2 positive, suggesting the need for more research.

Transit commuters in New York City. It would be desirable to analyze transit commuting in the same depth as auto commuting, but the sample was too small in all cities but New York. Finally, Table 5 shows the regressions to estimate speed, distance, and time for transit commuters in New York. These were compared to the row of results in Tables A1-A3 (a city by city analysis available from the authors) which looked at auto commuters in New York. First, speed: for New York's auto commuters, the higher the density the lower the speed, but for transit, just the opposite is true. Rail transit does not suffer the same congestion problems as the automobile, and the higher density provides a higher frequency of direct routes at least to $10,000 \mathrm{ppsm}$. Above that threshold, the effect of density on speed is insignificant. These results differ from the national results for transit, possibly due to New York's exceptional dependence on rail.

Second, distance: for auto commuters density is negatively related to distance in New York, this is true for transit commuters there too. This supports the national findings. Finally, time: for auto commuters in New York, above that value; however for the transit commuter, density is negatively 


\begin{tabular}{llll}
\multicolumn{4}{c}{ TABLE 5: TRANSIT COMMUTING IN NEW YORK CITY } \\
\hline Variable & $\begin{array}{c}\text { Time } \\
\text { (minutes) }\end{array}$ & $\begin{array}{c}\text { Speed } \\
\text { (MPH) }\end{array}$ & $\begin{array}{l}\text { Distance } \\
\text { (miles) }\end{array}$ \\
\hline ADULT & 14.87 & 0.945 & 3.71 \\
-2.7 & -0.25 & -1.06 & \\
MALE & 0.08 & 3.05 & 1.41 \\
-0.031 & -1.61 & -0.82 & \\
INCRAT & -0.936 & 1.21 & 2.09 \\
(-0.31) & -0.56 & -1.07 & \\
DENSLOW & -0.0025 & 0.0015 & -0.000362 \\
(-3.04) & -2.54 & $(-0.673)$ & \\
DENSHIGH & -0.0005392 & -0.00011 & -3.25 \\
(-4.73) & -1.37 & $(-4.43)$ & \\
R-Square & 0.08 & 0.07 & 0.09 \\
N & 272 & 272 & 272 \\
\hline
\end{tabular}

note: T-Statistic in parenthesis

related to time up to $10,000 \mathrm{ppsm}$, and positively related related to time at all densities. This confirms the findings with the national data (including New York).

\section{Summary and Conclusions}

This paper analyzes the magnitude and direction of the effects of residential density and other variables concerning urban form on travel parameters after controlling for demographic factors. It also reviews the relationship of density and demographics on each of 38 specific cities. The investigation into the relationship between travel behavior and density reveals some interesting results. While distance and speed are both negatively associated with density, auto travel time is negatively related to density below $10,000 \mathrm{ppsm}$ and positively related above $10,000 \mathrm{ppsm}$. The increase in travel time with density above $10,000 \mathrm{ppsm}$ indicates the possibility that beyond that threshold congestion increases making driving a less attractive option. Transit users display a negative relationship between travel time and density both above and below the $10,000 \mathrm{ppsm}$ density threshold. The declining transit time and increasing auto time above $10,000 \mathrm{ppsm}$ explains the evidence of higher transit mode share in high density areas.

Metropolitan growth is found to be positively related to travel time for auto commuters. This may indicate an inability of the public sector to provide transportation infrastructure concurrently with population growth. The ability of households and firms to mutually co-locate in growing suburbs with 
economies in travel time may, however, involve some time lag which is not considered in this analysis.

Cities oriented around freeways have higher average speeds and distances, but no significant relationship with time, reaffirming that individuals will adjust locations to take advantage of higher speeds made available by freeways while maintaining travel time. In addition, the presence of a rail system is associated with higher times and distances for auto commuters and lower speeds, due perhaps to infrastructure investment patterns or correlation between heavy rail and city size.

So it is found that though density has noticeable effects on speed and distance of trips, its effect on time is limited and contingent. A simple application of the standard transportation-location tradeoff in urban economics might miss factors which temper the importance of job markets on housing location and labor markets on firm location. For individuals choosing a residence, their relevant accessibility includes factors other than employment, such as access to family, schools, parks, shops, and the like. Household location decisions are complicated by multiple workers for whom location needs to be considered. For firms choosing location, access to the labor market may offset access to other firms. There are always lags in markets reaching "equilibrium" due to the transaction costs of relocation. Finally, the increasing returns associated with continuing physical placement in social and economic networks, such as the sunk nature of fixed costs in establishing contacts with friends, neighbors, business, and colleagues, are significant barriers to rapid relocation to shave a few minutes from a commute.

Use of these relationships for policy (for instance, to reduce the amount of congestion, gasoline usage, or air pollution) must be tempered by several caveats. First, the relationships of density cannot be isolated from selfselection bias. Individuals choose a density (or distance from the center) based in part on how much they want to commute and what lifestyle they wish to lead. Creating additional high density areas may not increase the number of people with certain commuting and lifestyle preferences. It certainly cannot be expected to increase the number of young singles or older retirees who most often inhabit high density apartments. Second, these relationships are particularly weak compared with total variation in commuting. Using density as a primary tool influencing commuting behavior seems an expensive approach to the problem. Third, though density is obviously associated with higher transit use, adding development (upping density) increases the number of auto trips so long as auto mode share is not zero, and in general, it is far from zero.

While density is an important explanatory variable, it is likely to be a much less important policy instrument to influence commuting behavior. The 
ability of policy-makers in relatively free markets to modify density is clearly marginal compared to the size of cities, the area which is relevant when considering commuting and labor markets. Furthermore, marginal changes in density are likely to cause even more marginal changes in commuting behavior. To be persuasive, arguments for higher density should rest on stronger grounds than their impact on journey-to-work travel.

\section{NOTE}

1. While in general, highway and transit funding come from separate pots of money, the Highway Act of 1973, and subsequent rules, allowed cities and states to trade money earmarked from the Highway Trust Fund for construction of interstate highway segments to general fund money used for transit (Smerk, 1991). More recently, the Intermodal Surface Transportation Efficiency Act of 1991 has enabled a greater deal of flexibility. To some extent, cities have had choices whether to invest in rail or highways for over 20 years.

\section{REFERENCES}

Bae, C.-H.C. 1993. Air quality and travel behavior: Untying the knot. Journal of the American Planning Association 59(1): 65-74.

Cervero, Robert. 1989. Jobs-housing balance and regional mobility. Journal of the American Planning Association 55(2): 136-50.

Dunphy, R.T., and K. Fisher. 1994. Transportation, congestion, and density: New insights. Washington DC: Urban Land Institute.

Frank, L.D., and G. Pivo. 1994. Impacts of mixed use and density on utilization of three modes of travel: Single occupant vehicle, transit and walking. Transportation Research Record 1466: 44-52.

Garreau, J. 1991. Edge cities: Life on the new frontier. New York: Doubleday.

Giuliano, G., and K.A. Small. 1991. Subcenters in the Los Angeles Region. Regional Science and Urban Economics 21: 163-82.

- 1993. Is the journey to work explained by urban structure? Urban Studies 30(9): $1485-1500$.

Goodwin, P. 1975. Variations in travel between individuals living in areas of different population density. Proceeding of a Seminar on Urban Traffic Models, July 7-11, Planning and Transportation Research and Computation (PTRC) Summer Annual Meeting, University of Warwick, England. London: Planning and Transport Research and Computation (International) (June).

Gordon P., H.W. Richardson, and H.L. Wong. 1986. The distribution of population and employment in a polycentric city: The case of Los Angeles, Environment and Planning $A$ 18: 161-173.

Gordon P., A. Kumar, and H.W. Richardson. 1989a Congestion, changing metropolitan structure and city size in the U.S. International Regional Science Review 12 (1): 45-56.

1989b. The influence of metropolitan spatial structure on commuting times. Journal of Urban Economics 26: 138-49.

- 1989c. Gender differences in metropolitan travel behavior, Regional Studies 23(6): 499-510.

Greene, D. 1980. Urban Subcenters: Recent trends in urban spatial structure, Growth and Change 11(1): 29-40. 
Handy, S. 1993. Regional versus local accessibility: Implications for non-work travel. presented at 72nd Annual Meeting of Transportation Research Board, Washington DC.

Hanks, J.W., and T.J. Lomax. 1993. Roadway congestion estimates and trends. Research Report 1131-4. Texas Transportation Institute, July.

Heikkila, E.P. J.I. Gordon, R.B. Kim, H.W. Peiser, H.W. Richardson, and D. DaleJohnson. 1989. What happened to the CBD-distance gradient?. Land Values in a polycentric city, Environment and Planning $A$ 21: 221-232.

Isard, W. 1956. Location and Space Economy, Cambridge MA: MIT Press, 76.

Levinson, D., and A. Kumar, 1995a. A multimodal trip distribution model: Structure and application. Transportation Research Record \# 1466: 124-31.

- 1995b. Activity, travel, and the allocation of time, Journal of the American Planning Association 61(4): 458-470.

McDonald, J.F. 1987. The identification of urban employment subcenters, Journal of Urban Economics 21: 242-258.

McDonald, J.F., and P. Prather. 1994. Suburban employment centers: The case of Chicago, Urban Studies 31: 201-218.

Mills, E.S. 1972. Studies in the structure of urban economy Baltimore: Johns Hopkins.

Mitchelson, R.L., and J.O. Wheeler. 1986. Analysis of aggregate flows: The Atlanta case. in The geography of urban transportation, edited by S. Hanson. New York: Guilford Press.

Newman P.W.G., and J.R. Kenworthy. 1992. Is there a role for physical planners? Journal of the American Planning Association 58 (3): 353-362.

Pas, Eric I. 1980. Toward the understanding of urban travel behavior through the classification of daily urban travel/activity patterns. Dissertation: UMI-81- 04755.

Pushkarev, B., and J. Zupan. 1977. Public transportation and land use policy. Bloomington: Indiana University Press.

Richardson, H. 1973. The economics of urban size. London: Saxon House.

Scott, A.J. 1988. Metropolis. Berkeley: University of California Press.

Sivitanidou, R. 1995. Do office firms value access to service employment centers? A hedonic value analysis within polycentric Los Angeles? presented at 34th Annual Meeting of the Western Regional Science Association, San Diego CA, Feb. 22-26.

Steiner, R. 1994. Residential density and travel patterns: Review of the literature. Transportation Research Record 1466: 37-43.

Smerk, G.M. 1991 The federal role in urban mass transportation. Bloomington IN: Indiana University Press.

United States Bureau of Census. 1984. Population and land area of urbanized areas for the United States and Puerto Rico. PC80-S1-14, Washington DC . 1991. Census Press Release 2.21.1991 CB91-66, Washington DC.

United States Department of Transportation. 1990. Nationwide personal transportation survey. Washington DC.

Voorhees and Associates. 1968. Factors and trends in trip lengths, National Cooperative Highway Research Report \# 48. Washington DC. 


\section{GROWTH AND CHANGE, SPRING 1997}

\begin{tabular}{|c|c|}
\hline Variable & Description \\
\hline ADULT & 1 if $17<$ age $<66,0$ otherwise \\
\hline AGE $16-20$ & 1 if age is $16-19,0$ otherwise \\
\hline AGE $20-30$ & 1 if age is $20-29,0$ otherwise \\
\hline AGE30-40 & 1 if age is $30-39,0$ otherwise \\
\hline AGE $40-50$ & 1 if age is $40-49,0$ otherwise \\
\hline AGE $50-60$ & 1 if age is $50-59,0$ otherwise \\
\hline AGE $60-70$ & 1 if age is $60-69,0$ otherwise \\
\hline AGE70+ & 1 if age is 70 or above, 0 otherwise \\
\hline DENSHIGH & $\begin{array}{l}\text { population density of residential zip code if density } \bullet 10,000 \\
\text { ppsm, } 0 \text { otherwise }\end{array}$ \\
\hline DENSLOW & $\begin{array}{l}\text { population density of residential zip code if density }<10,000 \\
\text { ppsm, } 0 \text { otherwise }\end{array}$ \\
\hline EDGECITY & number of edge cities in metropolitan area (after Garreau 1991) \\
\hline FREECITY & $\begin{array}{l}\text { proportion of metropolitan travel on freeways (from NPTS data } \\
\text { set) }\end{array}$ \\
\hline GROWRATE & percentage population growth from 1980 to 1990 \\
\hline INCRAT & household income (dollars)/ median metropolitan income \\
\hline MALE & 1 if male, 0 otherwise \\
\hline PD0-99 & 1 if reside in density class between 0 and $99 \mathrm{ppsm}, 0$ otherwise \\
\hline PD $100-249$ & $\begin{array}{l}1 \text { if reside in density class between } 100 \text { and } 249 \text { ppsm, } 0 \\
\text { otherwise }\end{array}$ \\
\hline PD250-499 & $\begin{array}{l}1 \text { if reside in density class between } 250 \text { and } 499 \mathrm{ppsm}, 0 \\
\text { otherwise }\end{array}$ \\
\hline PD500-749 & $\begin{array}{l}1 \text { if reside in density class between } 500 \text { and } 749 \text { ppsm, } 0 \\
\text { otherwise }\end{array}$ \\
\hline PD750-999 & $\begin{array}{l}1 \text { if reside in density class between } 750 \text { and } 999 \text { ppsm, } 0 \\
\text { otherwise }\end{array}$ \\
\hline PD $1000-1999$ & $\begin{array}{l}1 \text { if reside in density class between } 1000 \text { and } 1999 \text { ppsm, } 0 \\
\text { otherwise }\end{array}$ \\
\hline PD2000-2999 & $\begin{array}{l}1 \text { if reside in density class between } 2000 \text { and } 2999 \text { ppsm, } 0 \\
\text { otherwise }\end{array}$ \\
\hline PD3000-3999 & $\begin{array}{l}1 \text { if reside in density class between } 3000 \text { and } 3999 \text { ppsm, } 0 \\
\text { otherwise }\end{array}$ \\
\hline PD4000-4999 & $\begin{array}{l}1 \text { if reside in density class between } 4000 \text { and } 4999 \text { ppsm, } 0 \\
\text { otherwise }\end{array}$ \\
\hline PD5000-7499 & $\begin{array}{l}1 \text { if reside in density class between } 5000 \text { and } 7499 \text { ppsm, } 0 \\
\text { otherwise }\end{array}$ \\
\hline PD7500-9999 & $\begin{array}{l}1 \text { if reside in density class between } 7500 \text { and } 9999 \text { ppsm, } 0 \\
\text { otherwise }\end{array}$ \\
\hline PD10000-49999 & $\begin{array}{l}1 \text { if reside in density class between } 10000 \text { and } 49999 \text { ppsm, } 0 \\
\text { otherwise }\end{array}$ \\
\hline PD50000+ & 1 if reside in density class $50000 \mathrm{ppsm}$ or above, 0 otherwise \\
\hline RAILCITY & $\begin{array}{l}1 \text { if heavy rail present in metropolitan area (Atlanta, Baltimore, } \\
\text { Boston, Chicago, Cleveland, Miami, New York, Philadelphia, } \\
\text { San Francisco, Washington DC), } 0 \text { otherwise } \\
\text { urbanized area density (in ppsm) }\end{array}$ \\
\hline
\end{tabular}

